\title{
HIRSCHMAN Y LA DEPENDENCIA: EL ESLABÓN OLVIDADO
}

\author{
JOSEPH HODARA*
}

\section{IRONIAS DE LA CLEPTOMNESIA}

EN EL AMERICAN ECONOMIC REVIEW FECHADO en septiembre de 1964 apareció un comentario intrigante. Se refería a la paternidad de un índice de concentración que había sido considerado por economistas eminentes (Massell, Kindleberger, Michaely, Tinbergen) como una simple derivación del coeficiente de Gini. ${ }^{1}$ En verdad, el indicador fue propuesto originalmente por el autor del escueto comentario: A. O. Hirschman.

Efectivamente, en un escrito publicado en 1945, y que tocaré con amplitud más adelante, ${ }^{2}$ Hirschman elaboró este índice con el propósito de medir los efectos políticos de la estrategia de comercio exterior puesta en práctica por la Alemania nazi. Con su estilo particular, Hirschman atribuyó este olvido en el eslabonamiento -siempre complejo- de las ideas a la "crueldad del mundo" intelectual, que por tradición y norma es constantemente agitado por cuestiones de paternidad y de invenciones paralelas. ${ }^{3}$ En algunas circunstancias, la escabrosa competencia entre académicos se torna anómica y desordenada, y suele conducir al señalamiento imperfecto de los antecedentes de una idea e, incluso, a la franca omisión.

* Catedrático Principal en las Universidades de Tel Avivy Bar llán; Investigador Asociado de E1 Colegio de México.

$1 \mathrm{E}$ indice tenía la forma $\mathcal{\Sigma}(x i / x)^{2}$, donde $x i$ representaba el valor de las transacciones comerciales de un país con el bien $i$ durante un lapso, en tanto que $x$ simbolizaba el total de las transacciones.

2 A. O. Hirschman, National Power and Structure of Foreign Trade, University of California Press, 1980 (primera edición, 1945) (escrito en 1941-1942).

3 Al respecto véase R. Merton, "The Sociology of Science", Columbia University Press, 1973, que dilucida claramente el fenómeno de la palernidad, de las invenciones coincidentes, y de la cleptomnesia. 
A mi juicio, este caso es un ejemplo más de lo que R. Merton llamó, con fina ironía, la "cleptomnesia", esto es, el hurto (inocente o deliberado) de ideas ajenas, o bien la repetición, sin saberlo, de una misma idea que tuvo algún investigador durante su temprana juventud. En este último caso, el científico se estaría robando asi mismo.

Este fenómeno está muy difundido. He encontrado que el propio Merton incurrió en este desliz. Al sugerir el "efecto-Mateo" en los mecanismos de acumulación científica, Merton olvida curiosamente a Myrdal. Como se sabe, el tal efecto alude a la ventaja acumulativa y desproporcional que un científico "veterano" posee, bien por la edad, bien por una exhibición efectiva y selecta en los mercados intelectuales. De esta ventaja comparativa no goza obviamente el joven estudioso que todavía debe lograr reconocimiento y conocimiento en la estratificación extremadamente desigual de la ciencia.

Ahora bien, parece claro que el "efecto-Mateo" guarda afinidades con la "causalidad acumulativa" propuesta inicialmente por Myrdal en los años treinta en su texto clásico sobre el problema étnico norteamericano. Es materia de estudio por qué Merton ignoró o reprimió esta afinidad. Aquí hacemos un primer apunte al respecto.

También cabe subrayar que el propio Hirschman trató de descubrir y explicar la cleptomnesia porfiada que los teóricos del imperialismo han perpetrado en contra de Hegel. ${ }^{4}$ El filósofo alemán ya había vislumbrado los mecanismos de expansión comercial y colonial que se estaban montando en el siglo XIX al amparo de diversas racionalizaciones. Marx desatendió este aporte a pesar de que conocía con pormenores la obra hegeliana. Hirschman acude a categorías psicoanalíticas para excusar este "acto fallido". La omisión de las contribuciones de Hegel a la cuestión imperial habría sido causada por la ansiedad y la "impaciencia histórica" de Marx. Como el planteo de Hegel confería un margen de latitud al capitalismo, en tanto que Marx deseaba acercar su término, éste habría "reprimido" las ideas de Hegel sobre el asunto.

Nuestro ensayo se inscribe en el marco general de la cleptomnesia pero tiene dos objetivos específicos. Primero destacar el mérito de Hirschman en el enhebramiento de las categorías que se tradujeron ulteriormente en las diversas corrientes de la dependencia. Y segundo, que la reevaluación del texto de 1945 es importante no sólo por honestidad intelectual sino porque aquellas primeras ideas podrian haber ayudado a los "dependencistas" a esquivar algunos de los callejones sin salida que ellos mismos se han construido. No se trata aquí de emprender una apología de Hirschman (no la precisa) sino la de contribuir a una genuina acumulación científica. De todas las vertientes de la dependencia discutiré en particular los trabajos de Fernando $\mathrm{H}$. Cardoso. Por dos razones significativas. Por un lado, Cardoso tiene responsabilidad histórica en el encuadre de este modelo interpretativo y la ha asumido con elegancia y medida. Por otro, las versiones algo más vulgares de la dependencia ya han sido tratadas en otra parte ${ }^{5} \mathrm{y}$, en

4 Véase en R. Villarreal (comp.), Economía Internacional, A. O. Hirschman, "Hegel, el imperialismo y el estancamiento estructural", FCE México 1979, segundo tomo.

5 Véase J. Hodara, "La dependencia de la dependencia", en El fin de los intelectuales, Universidad F. Villarreal, Lima, Perú, 1973. 
tiempos recientes, por Halperín Donghi en forma concluyente. ${ }^{6}$ Cabe recordar que el propio Hirschman pasó revista apacible y nostálgica a su aporte de $1945,{ }^{7}$ mas no pretendió allí poner en tela de juicio la originalidad del análisis dependencista. Acaso pensó que le corresponde al historiador de las ideas redescubrir eslabones y deudas.

Es oportuna la siguiente digresión. La paternidad de las ideas involucra cuestio. nes harto complejas. En primer lugar, el trazo de las genealogías es con frecuencia arbitrario -y siempre imperfecto; depende principalmente de la "erudición imaginativa" de quien se aventura en este campo. En segundo lugar, sólo uná crítica documental y contextual cuidadosa puede revelarnos si un autor se refirió en verdad a la idea que posteriormente se le atribuye. Después de todo, apreciables segmentos de la crítica literaria se nutren de injustificadas imputaciones (e impugnaciones) que suelen sorprender al autor si todavía se encuentra entre los vivos. Muerto sus intenciones genuinas son asunto de acertijo más o menos inteligente. En fin, aun cuando el arco de los antecedentes es configurado con pul: sritud merced a un acto sobrio de erudición, los deudores intelectuales suelen confabularse para reprimir esos orígenes. Quieren ser obsesivamente "padres fundadores". En consecuencia, suelen erigir escollos para remontarlos, o bien hacen hincapié en diferencias triviales.

En el caso particular de la dependencia, el negligente descuido al Hirschman de 1945 yo no lo excuso en términos psicoanalíticos. Más bien me valgo de la psicología social cognitiva -en particular de los trabajos experimentales de León Festinger sobre la "dinonancia"- pues me ofrece una explicación más satisfactoria. El deseo de crear planteamientos genuinamente latinoamericanos fue tan poderoso que gestó compromisos emocionales con su presunta originalidad. Con el fin de evitar disonancias, algunos intelectuales se zafaron de los antecedentes, construyendo mercados intelectuales más o menos autónomos. Sólo autores contemporáneos afines a la dependencia (Frank, Cockroft, Sweezy, Barán, Magdoff) fueron recogidos. Así se gestó una alianza para la originalidad; mi propósito no es romperla sino colocar los términos en perspectiva y equilibrio, más allá de las emociones nacidas en el temor a la disonancia. La propensión compulsiva a la originalidad está en la raíz de la cleptomnesia.

En suma, la historiografía intelectual no es tarea liviana; requiere dones y destrezas en una medida no menor que la historiografía económica o que la psicohistoria. No puede ser una "historia de ondas cortas"."

\section{LAS TESIS DE HIRSCHMAN}

En aquel escrito retrospectivo de 1978 (véase nota 7), Hirschman se condujo con

6 T. Halperín-Donghi, "Dependency Theory and Latin American Historiography", Latin American Research Review, 17, 1, 1982.

7 En la colección indispensable de J. A. Caporazo, International Organization 32, invierno 1978, que contiene análisis importantes sobre la dependencia. También se reproduce en la edición reciente de su texto.

$8 \mathrm{Al}$ decir de F. Braudel en otro contexto. Véase su La historia y las ciencias sociales, Alianza Editorial, Madrid 1982, p. 53 (primera impresión 1968). 
hidalga modestia. Modestia en parte injustificada, puesto que dejó pasar la oportunidad de indicar sus primeras afinidades con algunos afluentes de la teoria de la dependencia. Ahora hay que recuperar el balance. Nótese que no sólo los dependencistas esquivaron el escrito de Hirschman; fue marginado también por algunas escuelas estructuralistas en economía y por las "realistas" (Morgenthau, Aron, Bouthoul) en las relaciones internacionales.

Pero la omisión de los dependencistas es sobresaliente, puesto que el uso político de las transacciones comerciales encaminadas a crear controles estratégicos es una de sus principales preocupaciones. $Y$ el descuido de Cardoso-Faletto es particularmente llamativo porque estos autores tienden a la indagación prolija. ${ }^{{ }^{*}}$

¿Cuáles son las tesis de Hirschman que considero pertinentes en el contexto del estudio de la dependencia y en correspondencia con los propósitos de este ensayo?

Su obra de 1945 no toca problemas de América Latina. Entonces era este economista un refugiado "taciturno y circunspecto" 10 que reiniciaba su vida profesional en los Estados Unidos. Su interés estaba en aquel tiempo centrado en el país que le fue inhóspito para las tareas intelectuales: las modalidades de la estrategia comercial puestas en práctica en Alemania nazi, con el objeto de maximizar lo que Perroux denominara, también desde aquel momento," el "efecto de dominación".

El escrito de Hirschman es breve y enjundioso, y ya anticipa esa elegante erudición que más tarde lo haría inconfundible. Los primeros dos capítulos aluden a los nexos entre comercio y poder nacional. En el corto plazo - recuerda- ciertamente existe una incompatibilidad relativa entre "mantequilla y armas", elección brutal que Goering señaló reiteradamente. Todo tiene un costo de oportunidad, diriamos ahora. Sin embargo, en un horizonte largo, los mercantilistas no dejaron de tener razón: abundancia y poder son reconciliables y hasta se refuerzan mu. tuamente. Hirschman se engolfa en los orígenes de este contrapunto. El juego entre la elevación del ingreso agregado y el incremento del poder colectivo puede abrir paso a la guerra entre sistemas nacionales y expansivos (como pensaba Fichte) o bien a la paz (conforme al razonamiento urbano de Adam Smith). El resultado concre to depende de las directrices particulares que guien el comercio, incluyendo tanto la físonomía como la configuración estructural.de los países destinatarios. En este contexto, Hirschman recuerda que Macaulay había preconizado la dispersión geográfica de los intercambios con el objeto de suavizar la dependencia con el pais hegemónico; si los importadores de un producto aumentan, también se dilata el margen de maniobra. ${ }^{12}$

9 Me refiero a F. Henrique Cardoso - E. Faletto, Dependencia y desarrollo en América Latina, Siglo XXI, XI eđición 1976 (primera edición 1969). 1968.

10 Así lo caracteriza L. Fermi en Ilustrious Inmigrants, The University of Chicago Press,

11 Véase F. Perroux, "The Domination Effect and Modern Economic Theory" (publicado en 1943) en K. W. Rothschild (ed) Power in Economics. Penguin 1971

12 Esta idea fue elaborada más tarde por M. Wionczek. Véase por ejemplo "The Pacific Market for Capital, Market and Information and its Possible Opening for Latin America", J. of Common Market Studies, 10, 1, 1971. Los interesados en detalles sobre la politica alemana respecto a control de cambios, acuerdos de pago, subsidios a las exportaciones y otros asuntos pueden consultar todavía con provecho a Ch. Bettelheim, La economía alema- 
Por otra parte, las ventajas y las debilidades de la reciprocidad comercial fueron discutidas en forma ponderada por Montesquieu; el perspicaz analista francés observó que los nexos entre sectores externos crean y consolidan grupos de interés dentro de los paises importadores, grupos que suelen armar complicidades y entendimientos con los países exportadores. Hay aquí un primer signo de transnacionalización que Marx vislumbró en su momento al estudiar la conducta del imperialismo británico. Nótese, en contraste, que esta tesis no contradice lasideas de Schumpeter quien, como se sabe, trató de deslindar entre capitalismo e imperialismo. Este último puede brotar en otros sistemas y épocas.

En cualquier caso, la preocupación de Hirschman es similar a la de los dependencistas de este tiempo: el desequilibrio estratégico que puede.inducir el comercio que se efectua entre dos naciones que cuentan con poder desigual. En este orden de ideas, Hirschman distingue entre el "efecto-oferta" (abastecimiento de bienes y servicios) y el "efecto-influencia" (el control estratégico engendrado por el comercio). Ambos efectos deben tenerse presentes al medir las ganancias relativas de un intercambio internacional. Hirschman menciona -referencia indispensable que elaboro en otro trabajo- ${ }^{13}$ que la teoría de los términos del intercambio ofrece bases para evaluar estas ganancias a través del tiempo. Por supuesto, todavía estaba lejos de percibir un "centro" y una "periferia", a pesar de que el tema ya había sido insinuado por un colega alemán en la década anterior. ${ }^{14}$

¿A quién daña en mayor grado la discontinuidad o diversión del comercio? Obviamente al pais débil. Para demostrar esta premisa, Hirschman no echa mano a categorías marxistas-leninistas sino que se queda en los linderos marshallianos. La economía neoclásica no descartó la posibilidad de "imperfecciones" monopólicas, incluso en el comercio exterior. El socio más poderoso genera problemas de ajuste en el menos diferenciado merced a la conjunción de los dos efectos indicados. Por añadidura, los importadores del país débil traban relaciones favorables con los centros de decisión del país exportador.

Una de las contribuciones más notables y pertinentes de Hirschman es el planteo esquemático de la política comercial alemana, incluyendo los instrumentos concretos que se inspiraron en una estrategia de dominación..$^{15}$ Ese esquema, si se mudan actores y fechas, posee una actualidad sorprendente. Está muy cerca de algunos argumentos de la ulterior reflexión cepalina y del desprendimiento dependencista representado por Cardoso-Faletto.

Otro asunto que Hirschmann intuyó en 1945 es la dinámica de la negociación bilateral en condiciones de monopolio, incluyendo el dominio de la información (tema que, como se sabe, Boulding y Arrow recogerán más tarde). También aquí el autor toca una variación de la dependencia.

El caso empírico que Hirschman examina-militante política comercial del gobierno alemán - podría haber servido de pauta en las investigaciones sobre los "centros". Pues la agresión comercial alemana no se limitó a la manipulación

na bajo el nazismo, Ed. Fundamentos, Madrid 1973 (dos volúmenes).

$13 \mathrm{~J}$. Hodara, Orígenes intelectuales del pensamiento de Raúl Prebisch, El Colegio de México (en preparación).

14 Me refiero a E. Wageman, Estructura y ritmo de la economia mundial, Editorial Labor, Madrid-Buenos Aires, 1933.

5 Hirschman, National Power. . . pp. 34 y 35. 
de las exportaciones; fue acompañada por la transferencia de técnicos y técnicas. Hirschman of rece pormenores sobre estos patrones, y no deja de mencionar las resistencias a esta estrategia que delineó Giovanni Preziosi ya en 1914, otro antecedente desapercibido. Si el análisis empírico de Hirschman se hubiera tomado en cuenta, tal vez el agotamiento térico e historiográfico de los dependencistas se podría haber esquivado. El tratamiento de subsidios, cárteles, monopolio y juegos monetarios merece la atención cuidadosa de Hirschman. No es así entre muchos dependencistas amantes de altisonancias y denuncias (no es el caso de Cardoso-Faletto).

Al final, Hirschman preconiza un reordenamiento de los vínculos comerciales e institucionales entre países como un medio de atemperar las asimetrías y la politización nociva del intercambio y de las inversiones. Tema que el Nuevo Orden recoge tardiamente. ${ }^{16}$

\section{LOS AFLUENTES DE LA DEPENDENCIA}

James y Bath hicieron un intento de clasificar los contenidos singulares y diferenciados de la dependencia. ${ }^{17}$ Las limitaciones de este ensayo son variadas pero tiene el mérito indudable de constituir un primer empeño de codificación. Para estos autores, la "teoría de la dependencia" (prefiero teorías o afluentes) puede resumirse en cuatro postulados: a) el subdesarrollo está íntimamente ligado con la expansión de los centros capitalistas; $b$ ) subdesarrollo y desarrollo componen un sistema unificado, una sumatoria de dos factores interrelacionadas; $c$ ) el subdesarrollo no es una etapa pasajera o el umbral indispensable que conduce al crecimiento sostenido. El rezago puede mantenerse todo el tiempo que la configuración asimétrica "cause" o "condicione" (los dependencistas difieren, entre otras cosas, en la postulación de la causalidad) los "efectos oferta e influencia"; d) por último, la dependencia no se circunscribe a las transacciones externas; los centros de decisión, la cultura y el aparato productivo del país débil son afectados por el "país hegemónico" (eufemismo que en el contexto cepalino refiérese a los Estados Unidos).

Estos postulados no fueron presentados como una "teoría", esto es, un cuerpo ordenado de hipótesis, sino como hechos porfiados y autoevidentes. Atrevimiento apresurado que Halperín Donghi censura con justeza en el trabajo ya citado.

En este marco general de postulados me concentraré en el texto clásico de Cardoso y Faletto. ${ }^{18}$ No aludiré a algunas versiones vulgares que críticos sobrios ya están demoliendo. ${ }^{19}$

E1 escrito mesurado de Cardoso-Faletto debe ser puesto en perspectiva. Distingo tres corrientes de reflexión que, a mi juicio, han modelado su fisonomía.

16 Incursioné en este campo en The Intellectual Origins of the New International Economic Order, Tel Aviv University, 1982.

17 D. James - R. Bath, "Dependency Analysis of Latin America", Latin America Research Review, 11, 3, 1976.

18 Véase nota 9.

19 Por ejemplo, D. Ray, "The Dependency Model of Latin America under development: The Basic Falacies", J. of Interamerican Study and World Affairs, 15, febrero 1973. 
Una es la tradición cepalina La obra no sólo fue concebida dentro de las paredes de esa institución sino que lleva su estampa singular. Recoge trabajos anteriores de la CEPAL desde el punto de vista del contenido; y en cuanto al estilo, emplea. con frecuencia giros, contrapuntos y eufemismos que caracterizan la labor intelectual de este organismo. ${ }^{20}$ Dos, el escrito pertenece al "estallido sociologista" de la CEPAL que se hizo notorio en los sesenta; la sabiduría de los economistas ya no era suficiente para entender los dilemas y escollos del desarrollo. Cardoso y Faletto tuvieron alguna participación en este detonante, y trataron de casar a Marx con Weber. Este eclecticismo les permitjó eludir las versiones terminantes pero simplistas de otros analistas. Finalmente, el texto refleja la disociación poulatina que Cardoso comenzó a sentir entonces respecto a los postulados clá. sicos y voluntaristas de la CEPAL. ${ }^{21} \mathrm{El}$ autor brasileño -conjeturo- percibió que organismos tegionales como la CEPAL tenian limitaciones intrínsecas dimanadas de los gobiernos que la habían constituido. ${ }^{22}$ Más aún, que los reordenamientos externos e internos auspiciados entonces por esta entidad descartaban otras opciones de desarrollo, que no contaban con simpatías gubernamentales. Cardoso estaba así dentro de la CEPAL pero en vías de salida. Supongo que deseaba entonces respirar "el aire azul" en otras partes, como dice la expresión borgiana, sin cortar lazos con el organismo materno. Como lo sabe todo "cepalino", es muy difícil romper el cordón umbilical con esta institución. Concretamente, la ruta "popular y revolucionaria" se le antoja a Cardoso como algo más que una posibilidad teórica, y capta que el modelo cepalino no le podría dar fácilmente un lugar. ${ }^{23}$

Cardoso habla en otra parte ${ }^{24}$ del "movimiento ecológico de las ideas". Ni el feudalismo ni el positivismo europeos llegan a estas tierras de América Latina en la versión original. Los mismos nombres se aplican a estructuras dispares. En verdạd Cardoso podría haber dicho que todo traspaso (geográfico como textual) es tergiversación y cambio. Hasta la de un poema. La tarea consiste entonces en cotejar cuidadosamente el original con sus transfiguraciones. Lamentablemente, Cardoso-Faletto no lo hicieron pues, entre otras cosas, olvidaron el trabajo seminal de Hirschman. También tuvo alcance modesto el trabajo empírico de los autores, trabajo que respondía a las tradiciones cepalinas y no a la pormenorizada historiografía económica y social. Por ello decimos que Hirschman ofreció pautas que desafortunadamente se extraviaron.

El texto clásico de Cardoso-Faletto persigue, como se sabe, un análisis "integrado" del desarrollo, vale decir el empalme sistemático de variables sociológicas, económicas e historiográficas. Análisis que ya estaba presente en Hirschman, y que $O$. Spann habia insinuado en los veínte, en su crítica virulenta al marginalis-

20 A estos giros hemos llamado "contrapuntos semióticos". Véase nota 13.

21 Es interesante señalar que chispas de esta disociación se encuentran en los temas recientes de Raúl Prebisch, que difieren radicalmente de la época inicial del organismo que animó.

22 Sobre estas restricciones véase mi trabajo, "Aportes, directrices y limitaciones latinoamericanas para la ciencia y la tecnología", en Comercio Exterior (en prensa).

23 Véase F. H. Cardoso, "Imperialismo y dependencia en América Latina", en R. Villarreal, op. cit. En este texto, publicado en 1972, trata de postular "nuevas formas de dependencia" que difieren te la visión leninista. Su estilo es discretamente militante.

24 F. H. Cardoso, "La originalidad de la copia", Revista de la CEPAL, 2, 1977. 
mo. ${ }^{25} \mathrm{El}$ ensayo de Cardoso-Faletto fue original sin duda, mas en un contexto de negligencia bibliográfica.

Los autores latinoamericanos discuten lúcidamente estructuras y procesos internos, como el anticipo de la urbanización, la segmentación de los mercados, la "precocidad" del consumo, y el ascenso de reinvindicaciones populares. La descripción no fue original sino el énfasis enmarcado en una doctrina más o menos coherente. También subrayaron la importancia de la lucha de grupos y clases dentro de la sociedad -y lo que es más interesante dentro del Estado latinoamericano. No son $\tan$ ingenuos ni $\tan$ mecanicistas como para soslayar los juegos dialẻcticos entre procesos y estructuras, entre vínculos externos y configuraciones nacionales. Otra deuda inocente con Hirschman. Cardoso y Faletto objetan un deslinde entre centro y periferia que sea funcional y neutro; pretenden descubrir la carga política que contiene. El señalamiento fue correcto sin duda, aunque dependencistas vulgares hicieron de esta politización un maniqueísmo tenaz que ya se está filtrando en los ochenta en grupos juveniles, en la forma de un "chejumeinismo" peculiar. Ciertamente, Cardoso-Faletto no tienen responsabilidad intelectual por estos desatinos, como a Nietzsche no se le puede adjudicar la demencia hitleriana. Es la ironía de la historia, como I. Berlín no se cansa de sub. rayar en otros contextos.

Cardoso y Faletto apuntan con esmero que algunos sistemas nacionales tienen márgenes de latitud determinados bien por la dotación de factores, bien por la articulación histórica de una burguesía nacional. También acentúan el significado de las clases medias en proceso de crecimiento, acento plenamente justificado cuando se contempla el desenvolvimiento industrial europeo.

El brote del "Estado desarrollista" guarda afinidades con el tipo de economia establecida por los alemanes en los treinta. Y también las contradicciones internas que fueron apreciables en el caso aleman. ${ }^{26}$ Ciertamente, le faltó, en general, al Estado desarrollista latinoamericano un impulso expansivo hacia afuera; éste no persiguió "espacios vitales". La diferencia es importante, al menos hasta el momento. Pues el reflorecimiento de la geopolítica en América Latina puede causar sorpresas.

\section{Hacia la reconstrucción teórico-empirica de la dependencia}

No es ningún secreto que algunos afluentes de la dependencia se han secado completamente. ${ }^{27}$ No así el esquema analítico de Cardoso-Faletto que todavía encierra algunas potencialidades, si los temas por ellos discutidos son tallados con virtuosismo. Esta corriente necesita, en el espiritu de Lakatos, un programa

25 Para una revista breve a las ideas de $\mathrm{O}$. Spann véase $\mathrm{E}$. James, Historia del pensamiento económico en el siglo $X X, \mathrm{FCE}$, México 1957, pp. 94-100.

$26 \mathrm{Al}$ respecto véanse las entrevistas hechas a un investigador conspicuo de ese periodo como G. Mosse, Nazism, Transaction Books, New Brunswick, New Jersey, 1978.

27 Para fundamentar este aserto véanse la compilación de J. A. Caporazo citada en la nota 7 y el Latin American Research Review, 17, 1, 1982. La transferencia geográfica de la dependencia no ha tenido buena fortuna. Como ejemplo véase M. Lacheraf, "La cultura entre la ideología colonial dominante y la ideología de liberación de los pueblos", Estudios de Asia y Africa, 52, abril-junio 1982, que escasamente supera el anälisis mecanisista hecho por C. Leys, en Underdevelopment in Kenya, Heineman, Londres, 1977. 
de investigaciones que contribuya a la reconstrucción intelectual. Siguen algunas sugerencias en este sentido.

En primer lugar, cabe definir con mayor cuidado el enlace entre política y economia, entre la "pugna distributiva" y la acumulación de capital (usando el último lenguaje prebischiano). Hay que trascender las frases hechas; de lo contrario el análisis dependencista en este campo muy poco superará (y es probable que se quede por debajo) de la obra clásica e injustamente olvidada de Carr. ${ }^{28}$

En segundo lugar, esta rama fértil de la dependencia debería adoptar mayor profundidad bibliográfica. Y no me refiero sólo a Hirschman o a Spann. Tengo la impresión de que los exámenes de Ricardo sobre la distribución del ingreso han sido sistemáticamente descuidados, empobreciendo el acervo teórico. Prebisch los está redescubriendo.

Tercero, esta versión de la dependencia debería fomentar una historiografía esmerada, fundada en nuevos conceptos y en el cotejo preciso de documentos. Laclau ${ }^{29}$ ofrece una pauta en esta esfera, que se apoya en el marco teórico elaborado por Flichman. ${ }^{30}$

Cuarto, este enunciado dependencista debería lidiar porfiadamente con un viejo tema de la CEPAL: el progreso técnico. Es obvio que las tecnologías avanzadas habrán de modificar variables clave de la dependencia, como la distribución del trabajo industrial, las facultades manipulativas del Estado, el brote del desempleo abierto, y la multiplicación de los efectos de demostración. Aquí tiene la dependencia una veta para rejuvenecerse.

Finalmente, es imperativo estudiar con mayor tino y empeño las nuevas formas del capitalismo industrial. No es ni ogro explotador ni filantropia condicionante (si O. Paz me permite la licencia). Este capitalismo está adquiriendo modalidades inéditas de integración, complementación y reacción; ${ }^{31}$ gracias al progreso técnjco y a sus políticas económicas, los sistemas industriales podrían prescindir de las materias primas y hasta de la transferencia geográfica de industrias obsoletas. Hay una nueva constelación en los ochenta, que esta vertiente de la dependencia - por su mesura y lucidez-debería desentrañar, si es que todavía pretende llegar a un entendimiento algo más completo de la industrialización sustitutiva, del reparto del ingreso, y de la latitud de los centros locales de decisión. En cualquier caso, hay que poner punto final a las generalizaciones prestadas, a los rencores predilectos y a los romanticismos autoritarios. La versión Cardoso-Falet to todavía puede enriquecerse.

28 Carr E. H., The Twenty Years' Crisis, MacMillan, London, 1971.

29 E. Laclau (h), "Modos de producción, sistemas económicos y población excedente", en M. Giménez Zapiola (comp.), El régimen oligárquico, Amorrortu, Bs. As., 1975.

$30 \mathrm{G}$. Flichman, La renta del suelo y el desarrollo agrario argentino, Siglo XXl, México 1977.

31 Signos de estas modalidades fueron señaladas en mi reseña al "Informe de la OECD sobre progreso técnico y crecimiento", Economía y demografía, XV, 46, 1981. 